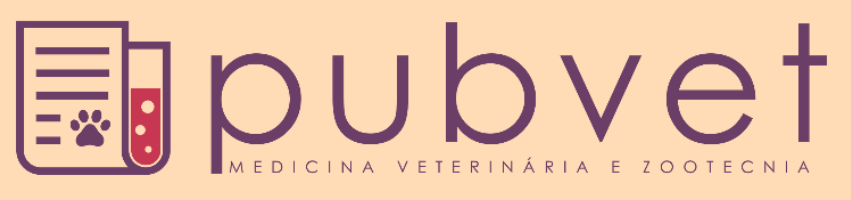

https://doi.org/10.31533/pubvet.v14n12a706.1-6

\title{
Avaliação do conhecimento da população sobre a doença leptospirose
}

\author{
Bianca Man Tchuin Chang Lee ${ }^{1}$, Giovanna Pazetti ${ }^{1}$, Isabella Martins Cattin ${ }^{1}$, Marinna Moraes \\ Sordi $^{1}$, Vítor Micchi Pilon ${ }^{1}$, Vitória França Gonçalves ${ }^{1 *}$, Ed Wilson Santos ${ }^{20}$
}

${ }^{I}$ Discente da Faculdade de Medicina Veterinária da Universidade Anhembi Morumbi, São Paulo, São Paulo, Brasil.

${ }^{2}$ Docente da Faculdade de Medicina Veterinária da Universidade Anhembi Morumbi, Departamento de Imunologia e Parasitologia, São Paulo, São Paulo, Brasil.

*Autor para correspondência, E-mail: vitoriafranca.vet@gmail.com

Resumo. O presente estudo teve como objetivo fazer um levantamento do conhecimento da população acerca da zoonose leptospirose, na qual foram entrevistadas 684 pessoas de diferentes idades, ocupações e condições de moradia. Devido a circunstância do isolamento social decorrente da pandemia de Covid-19, utilizamos o método de entrevista remota Google Forms. Buscamos reunir diferentes profissionais, tentando associar suas respostas as de profissionais da saúde também questionados, para que fosse avaliada a discrepância ou equivalência das respostas, de acordo com o grau de conhecimento de cada grupo em relação a Leptospirose. Após a realização do questionário, foi disponibilizado um folder digital com as informações corretas sobre a doença, visando conscientizar a população. A bactéria Leptospira é o agente responsável pela infecção da Leptospirose, que se adapta em ambientes úmidos e quentes. Os principais reservatórios da doença são os roedores sinantrópicos que eliminam o agente pela urina. Por isso, condições de baixo saneamento básico e áreas de inundações são áreas de risco que propiciam a infecção. Sendo importante que a população tenha um conhecimento mínimo acerca da doença para poder preveni-la e com isso, combater os focos de contaminação. O nosso estudo teve acesso ao conhecimento de pessoas de diferentes ocupações com intuito de avaliar se as campanhas governamentais estão sendo efetivas com a oferta de informação e conscientização.

Palavras-chave: educação ambiental, leptospirose, levantamento, saúde pública, zoonose

\section{Evaluation of population knowledge about leptospirosis disease}

Abstract. The present study aimed to survey the population's knowledge about leptospirosis zoonosis, in which 684 people of different ages, occupations, and housing conditions were interviewed. Due to the circumstance of social isolation resulting from the Covid-19 pandemic, we used the Google Forms remote interview method. We sought to bring together different professionals, trying to associate their responses with those of health professionals also questioned, so that the discrepancy or equivalence of responses could be assessed, according to the degree of knowledge of each group about leptospirosis. After completing the questionnaire, a digital folder was made available with the correct information about the disease, aiming to raise awareness among the population. The Leptospira bacterium is the agent responsible for Leptospirosis infection, which adapts in humid and hot environments. The main reservoirs of the disease are synanthropic rodents that eliminate the agent through urine. For this reason, conditions of low basic sanitation and areas of floods are areas of risk that appropriate the infection. It's important that the population has a basic knowledge about the disease to prevent it and, with that, fight the contamination points. Our study had access to the knowledge of people from different 
occupations to assess whether government campaigns are being effective with the provision of information and awareness.

Keywords: environmental education, leptospirosis, public health, survey, zoonosis

\section{Introdução}

A leptospirose é uma zoonose de importância mundial e um problema de saúde pública no Brasil (Souza et al., 2011). Como a leptospirose tem sintomas inespecíficos, como cefaleia, febre, dores musculares, podendo envolver também náuseas e vômitos, pode ser confundida com outras doenças de patógenos diferentes como virais (Marinho, 2012; Souza et al., 2011). A doença pode evoluir para uma forma pulmonar, gerando síndrome de angústia respiratória, podendo ser fatal (Marinho, 2012).

A bactéria Leptospira é a responsável por causar a infecção, sendo ela uma espiroqueta causadora de doença aguda (Marinho, 2012). São considerados reservatórios dessa doença animais que são capazes de eliminar o patógeno na urina, sendo os roedores sinantrópicos o principal grupo responsável pela transmissão, principalmente urbana (Marinho, 2012; Soares et al., 2014). A transmissão ocorre por contato direto ou indireto à urina infectada, podendo penetrar pelas mucosas, feridas de pele ou quando esta estiver com poros dilatados (Marinho, 2012; Simões et al., 2016).

Assim, a leptospirose é considerada uma doença endêmica de locais com baixo saneamento básico e locais de frequentes inundações (Soares et al., 2014). Segundo o Boletim Epidemiológico da Secretaria de Vigilância em Saúde, inundações são a segunda causa de desastres ambientais no Brasil e atingem todas as regiões. Segundo dados do Ministério da Saúde, no ano de 2018 o Brasil registrou 3.056 casos de leptospirose, dos quais 280 evoluíram para o óbito. No ano de 2019 foram 3.368 casos confirmados, dos quais 280 evoluíram para o óbito (BRASIL, 2020).

O tratamento deve ser feito com antibioticoterapia, sendo os fármacos de utilização penicilina, ceftriaxone ou cefotaxime. Em casos mais graves, é necessário cuidado intensivo em internações e UTI's, principalmente quando ocorrer hemorragia pulmonar e acometimento renal (BRASIL, 2014; Daher et al., 2010).

Segundo o ministério da Saúde, a prevenção da leptospirose deve ser feita com obras de saneamento básico, melhoria nas habitações humanas e no controle de roedores. Também, é recomendado evitar contato com água ou lama de inundações. Para os profissionais que podem ser expostos à leptospirose (os que trabalham na limpeza de lamas, entulhos e desentupimento de esgotos), é recomendado uso de botas e luvas de borracha (BRASIL, 2014).

Este trabalho foi realizado para realizar uma análise comparativa sobre o conhecimento de duas parcelas da população sobre a Leptospirose, sendo as pertencentes a área da saúde (profissionais e estudantes) e os que não se declaram da área da saúde. A partir de perguntas mais específicas sobre essa afecção foi possível observar a discrepância ou a equivalência nas respostas desses dois grupos por meio de gráficos e tabelas presentes. Com isso, objetivou a conscientização dos mesmos, seja apresentando a definição de zoonoses, relatando a transmissão do agente ou apontando quais as medidas preventivas. Ou seja, passar a informação correta (contendo informativo pós questionário), sendo de suma importância para manter a população informada acerca da Leptospirose. Destacando a importância da pesquisa científica, principalmente no Brasil.

\section{Material e métodos}

Foi utilizado um questionário na plataforma Google Forms como ferramenta remota para a realização dessa pesquisa, visto a pandemia da covid-19 e o consequente isolamento social, impedindo a realização do questionário de forma presencial. Foram entrevistadas 684 pessoas, de diferentes idades, ocupações e condições de moradia. Buscamos reunir diferentes profissionais, tentando associar suas respostas às de profissionais da saúde também questionados, para que fosse avaliada a discrepância ou equivalência das respostas, de acordo com o grau de conhecimento de cada grupo em relação a doença leptospirose. Após a realização do questionário, foi disponibilizado um folder digital com as informações corretas sobre a doença, visando conscientizar a população. 
Do total (684), a maioria foi de jovens entre 15 a 22 anos de idade $(59,4 \%)$, seguido pelas idades de 23 a 35 anos (23,8\%), 51 anos ou mais $(8,9 \%)$ e por fim, os com 36 a 50 anos $(7,9 \%)$, representando o grupo com a menor participação.

Quanto as suas ocupações correspondentes, a maioria estudantes, não se identificaram pertencendo a área da saúde, assinalando a opção "Estudante de outra área" (33,9\%). Já o grupo com a segunda maior porcentagem se disse pertencente a área "Estudantes da área da saúde", sendo 28,4\%, seguidos pelos profissionais de outras áreas $(21,3 \%)$ e o último grupo com o menor destaque entre os quatro principais foram os próprios profissionais da área da saúde $(10,2 \%)$. Também puderam ser relatadas outras ocupações pelos entrevistados em um campo específico determinando o grupo "outros", que correspondeu a uma porcentagem de $6,2 \%$ do total, tendo um menor destaque numericamente.

Dessa forma, para que possamos entender a possível discrepância de conhecimento geral sobre essa afecção, dividimos as respostas dos entrevistados em dois grupos distintos. Os que se identificaram como profissionais da área da saúde, junto aos estudantes desta mesma área, somando um total de 264 pessoas (38,6\% do total), formando então o grupo da área da saúde. Já o outro grupo teve sua origem com base nas diferentes ocupações que não ligadas a área da saúde, juntamente a estudantes também de diferentes áreas, sendo formado por 378 pessoas (55,2\% do total). Esses dois grupos correspondem a $93,8 \%$ dos entrevistados, já que não incluímos as pessoas que se intitularam pertencentes a demais ocupações ("outros"), que como já dito, corresponderam a $6,2 \%$ do restante total.

A porcentagem de pessoas que vivem em áreas urbanas, onde a Leptospirose é majoritariamente presente atingiu um índice de $98,2 \%$ dos questionados, consequentemente a minoria $(1,8 \%)$ se declarou pertencente a área rural. É exatamente esse o cenário da prevalência dos locais mais acometidos (áreas urbanas), a infecção se dá pela exposição frequente a enchentes e ausência de saneamento básico, que propiciam a proliferação de roedores sinantrópicos, favorecendo a persistência e disseminação da bactéria (Soares et al., 2014). Sabendo disso, os entrevistados foram indagados sobre os alagamentos constantes na área em que residem e, 78,9\% alegaram que não há alagamentos constantes no seu local de moradia, já 21,1\% do restante alegaram que sim, sofrem com essa desvantagem de infraestrutura.

Junto a esses dados coletados e a essas perguntas estratégicas adotadas na pesquisa, outro influenciador como já citado anteriormente tem forte relação com a incidência dessa zoonose. Assim, nesse mesmo contexto, em outra pergunta $98,4 \%$ declararam que suas regiões específicas possuem saneamento básico, e a ausência desse dever do estado se mostrou em 1,6\% dos casos do total, o que acarreta para mais riscos a essa população.

\section{Resultados}

É de extrema importância que saibamos quão bem informada a população se encontra referente a este assunto. Assim, quando foi perguntado o que era uma zoonose (Figura 1), 52,8\% disseram que sabiam o que significava e concordaram com a seguinte frase: "É uma doença transmitida de animais para humanos".

Você sabe o que é uma zoonose?

684 respostas

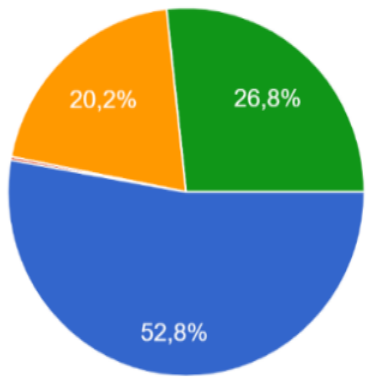

Sim, é uma doença transmitida de animais para humanos

Sim, é uma doença transmitida de humanos para animais

Sim, é uma doença transmitida de animais para humanos e de humanos para animais

Não

Figura 1. Conhecimento sobre o que é zoonose. 
Em 26,8\% das respostas, afirmaram que não sabiam o que tal palavra significava. Já 20,2\% das pessoas assinalaram que "sim", conheciam o termo e o significado, assinalando a seguinte resposta: "É uma doença transmitida de animais para humanos e de humanos para animais", sendo esta, a alternativa considerada correta. E a expressiva minoria $(0,3 \%)$ assinalou que "sim", sabiam o que a palavra significava, sendo "uma doença transmitida de humanos para animais". Observando as respostas, conclui-se então, que $20,2 \%$ do total de pessoas entrevistadas nesse método geral avaliativo obtiveram um melhor conhecimento a respeito desse termo.

Dos entrevistados $(99,9 \%)$ afirmaram que já tinham ouvido falar a respeito da Leptospirose. A respeito da transmissibilidade (Figura 2), foi feita a seguinte pergunta: "Sabe como é realizada a transmissão da leptospirose?". Assim, cerca de $88,2 \%$ responderam que a transmissão se dá pelo "contato com a urina de um animal infectado", enquanto que 5,1\% acham que basta o "contato direto com um roedor" para contrair a leptospirose.

Sabe como é realizada a transmissão da Leptospirose? 684 respostas
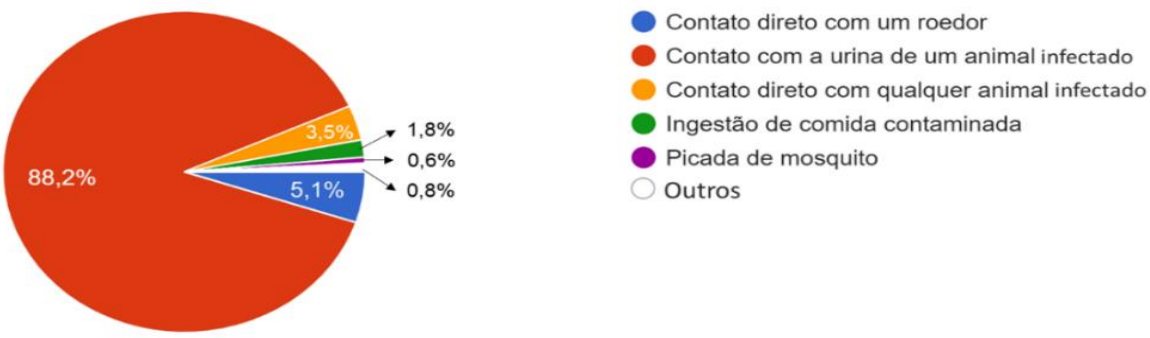

Figura 2. Conhecimento da transmissão da leptospirose.

A alternativa "o contato direto com qualquer animal infectado" foi a escolha para 3,5\% das pessoas, e a alternativa "ingestão de comida contaminada" correspondeu a $1,8 \%$ dos casos apresentados respondidos e apenas $0,6 \%$ do total acreditam que a leptospirose é transmitida "pela picada de mosquito". Um "outro" campo de resposta foi ofertado com o objetivo de abrangermos as informações colhidas, o entrevistado tinha a opção de apresentar outra(s) forma(s) de transmissão que ele(a) julgaria como correto. Obtivemos um resultado de $0,8 \%$ em relação a essas respostas, que incluíram discursivamente: "infecção na pele; não sei".

Em relação a incidência de casos e de como podem vir a ocorrer, foi criado um quadro onde poderiam ser assinaladas mais de uma alternativa (opções que poderiam estar corretas ou não). A maioria das pessoas responderam corretamente que condições de baixo saneamento básico $(94,6 \%)$ e áreas de alagamento (84,5\%) são importantes nesse quesito. Apesar do baixo número de pessoas que assinalaram a alternativa que dizia sobre "A ingestão de vegetais mal lavados" (19,7\%), esta é uma das responsáveis pelo acometimento da doença e também é considerada uma resposta correta. A minoria, erroneamente, assinalou que a ingestão de carne de má procedência $(7,0 \%)$ e áreas com muitos mosquitos $(2,2 \%)$ são motivos de preocupação para a disseminação da Leptospirose.

Observamos que a grande maioria reconhece que os roedores são os verdadeiros reservatórios da Leptospirose (98\%) e apenas $2 \%$ das pessoas assinalaram outras opções de respostas, entre elas a de que os humanos são os reservatórios $(1 \%)$, ou mosquitos $(0,9 \%)$ ou ainda os animais domésticos $(0,1 \%)$.

A sexta pergunta do estudo também mostrava alternativas referente a espécies que poderiam ter susceptibilidade a doença. Optamos por deixar todas as alternativas corretas como opções de resposta. Os resultados mostraram que, segundo os entrevistados, os humanos seriam os mais susceptíveis $(89,8 \%)$, seguidos de roedores $(66,3 \%)$, cães $(47,6 \%)$, gatos $(39,9 \%)$, bovinos $(25,4 \%)$, suínos $(24,4 \%)$ e por fim, os menos votados porém igualmente susceptíveis, equinos $(22,6 \%)$.

Com base na sua etiologia, o estudo requeria apenas uma alternativa correta. E nessa sétima questão em específico, 69,6\% responderam corretamente que a Leptospirose provém de uma bactéria. Outros $13,9 \%$ disseram que o protozoário é o responsável por essa infecção, seguidos de vírus $(12,4 \%)$ e de verme $(4,1 \%)$. 
A oitava pergunta fazia menção aos sintomas precoces apresentados pelos humanos ao contraírem a Leptospirose. Resultando em 85,4\% das pessoas assinalando a opção correta em relação aos sintomas: "Febre, dor de cabeça, dores musculares, falta de apetite, náuseas e vômitos". A segunda alternativa com maior porcentagem dos votos dizia que esses sintomas se baseavam em "regiões periféricas amareladas com evolução para necrose" $(9,2 \%)$. "Apenas dor de cabeça e leve aumento de temperatura" somou $3,1 \%$, ao mesmo tempo que coceira de pele obteve $1,8 \%$ e apenas uma síndrome gripal levou a minoria dos votos somando $0,6 \%$ do total.

Também abordamos, não só a pergunta sobre os sintomas precoces, mas também o que se diz respeito às complicações da Leptospirose. Sintomas como icterícia (pele amarelada), insuficiência renal e hemorragias estavam presentes no questionário em uma alternativa, sendo esta assinalada por $77 \%$ das pessoas, respondendo corretamente à questão. As incorretas variaram entre "Paralisia de membros" (9,2\%), "Úlceras de pele" (5,8\%), "Apenas mialgia" (5,3\%) e "Espirros e tosse" $(2,6 \%)$.

A décima pergunta questionava sobre o tratamento específico para esta doença, que, se baseia em antibióticos e UTI em casos graves, que como forma de alternativa, recebeu $66,1 \%$ das respostas. Apesar da maioria ter respondido corretamente, um grande número de pessoas não sabia responder qual a alternativa correta, portanto, o campo "não sei" foi a segunda maior parcela de respostas assinaladas $(25,7 \%)$. A terceira maior contagem de respostas conteve $6,9 \%$ dos votos, e dizia que "Soro com anticorpos" seria a melhor opção para esses pacientes. E com apenas 1,3\%, a "Vacina", foi a menos votada entre todas. Não obtivemos respostas advindas da alternativa "Apenas oxigenioterapia".

Por fim, na última questão, foram dispostas em forma de alternativas algumas medidas de prevenção (Figura 3). Algumas alternativas erradas e outras certas acerca da pergunta: "Quais as medidas de prevenção poderiam ser tomadas?". Pôde ser assinalada mais de uma alternativa neste caso. Tendo como resultado, 90,2\% das pessoas concordando que "Evitar contato com água ou lama de enchentes" seria o correto. A alternativa "controle de roedores" também teve um número expressivo de respostas $(82 \%)$. A "Utilização de EPI's por parte de profissionais da limpeza de esgotos e galerias" foi assinalada em $71,3 \%$ dos questionários, sendo que essas 3 respostas são medidas importantes que auxiliam no combate da Leptospirose (Figura 3).

\section{Quais as medidas de prevenção poderiam ser tomadas?}

684 respostas

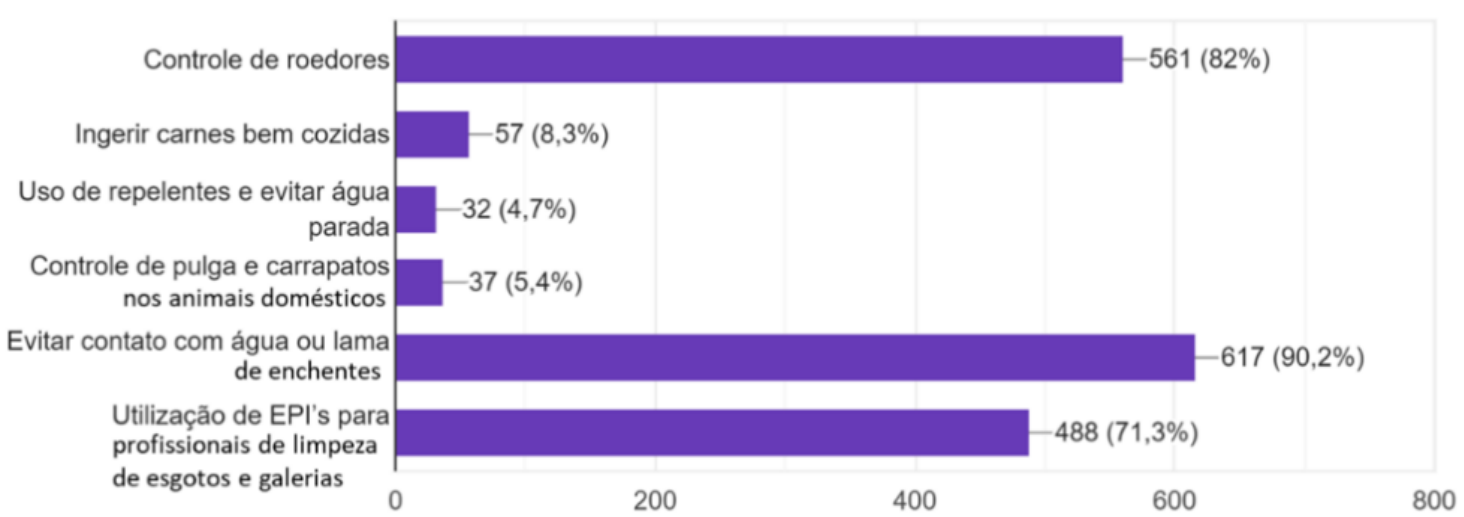

Figura 3. Conhecimento da prevenção da leptospirose.

As demais alternativas, que incluíam "Ingerir carnes bem cozidas", "Controle de pulgas e carrapatos nos animais domésticos" e "Uso de repelentes e evitar água parada" foram as alternativas que tiveram menor índice de concordância entre o público geral, $8,3 \% ; 5,4 \% ; 4,7 \%$, respectivamente.

Para uma análise mais específica dividimos o número total de pessoas em dois grupos de acordo com a sua ocupação, presumindo que as respostas seriam equivalentes as áreas que ocupam, portanto, pudemos observar os resultados para as perguntas na Tabela 1 . 


\section{Discussão}

Com a realização deste questionário, foi possível observar que a maioria das pessoas entrevistadas tinham um conhecimento mediano sobre a doença. Ao separar em dois grupos, sendo um de pessoas da área da saúde (profissionais e estudantes) e outro com pessoas de outras áreas (profissionais e estudantes), observamos que o grupo da área da saúde obteve a maior porcentagem de acertos em todas as perguntas no estudo, portanto maior conhecimento sobre a leptospirose. Já o grupo de pessoas de outras áreas, que apesar de não terem contato frequente acerca do assunto tratado, mostraram-se medianas de uma forma geral quando apontadas por elas as respostas corretas. Ou seja, apesar das pessoas da saúde terem se sobressaído na pesquisa, a outra parcela também dispunha de certo grau de conhecimento. Ainda assim, disponibilizamos um folder digital para todos os participantes com o fim de informá-los corretamente sobre a leptospirose, sanando possíveis dúvidas.

Tabela 1. Resultados das perguntas respondidas corretamente correlacionando com a ocupação dos participantes.

\begin{tabular}{|c|c|c|c|c|}
\hline \multirow{2}{*}{ Perguntas } & \multicolumn{2}{|c|}{ Área da saúde } & \multicolumn{2}{|c|}{ Outra área } \\
\hline & R. C. & $\%$ & R. C. & $\%$ \\
\hline Você sabe o que é uma zoonose? & 79 & $29,9 \%$ & 54 & $14,3 \%$ \\
\hline Sabe como é realizada a transmissão da Leptospirose? & 241 & $91,3 \%$ & 328 & $86,8 \%$ \\
\hline A qual (quais) tipo (s) de situação (ões) você acha que esta doença está associada? & 166 & $62,9 \%$ & 206 & $54,5 \%$ \\
\hline Qual o principal reservatório da Leptospirose? & 260 & $98,5 \%$ & 370 & $97,9 \%$ \\
\hline Quais espécies você acredita que podem ser acometidas? & 51 & $19,3 \%$ & 44 & $11,6 \%$ \\
\hline A Leptospirose é causada pela Leptospira, sendo esta um (a) & 202 & $76,5 \%$ & 245 & $64,8 \%$ \\
\hline Quais os principais sintomas precoces em humanos? & 235 & $89,0 \%$ & 315 & $83,3 \%$ \\
\hline Quais as principais complicações da leptospirose em humanos? & 219 & $83,0 \%$ & 277 & $73,3 \%$ \\
\hline Qual o tratamento para casos confirmados? & 204 & $77,3 \%$ & 221 & $58,5 \%$ \\
\hline Quais as medidas de prevenção poderiam ser tomadas? & 163 & $61,7 \%$ & 160 & $42,3 \%$ \\
\hline
\end{tabular}

R. C. - Respostas corretas

Mesmo com o conhecimento da população se mostrando satisfatório, ainda tiveram pessoas que não souberam responder algumas questões ou responderam de forma incorreta. Por isso, reforçamos, por meio deste trabalho, a importância de campanhas governamentais, principalmente sobre a transmissão e riscos da leptospirose, pois é uma doença de importante relevância em saúde pública tanto na área de veterinária quanto nas demais áreas da saúde.

\section{Referências bibliográficas}

BRASIL. (2014). Ministério da Saúde. Fundação Oswaldo Cruz. Instituto de Tecnologia em Imunobiológicos Bio-Manguinhos. Leptospirose: sintomas, transmissão e prevenção. www.bio.fiocruz.br

BRASIL. (2020). Ministério da Saúde. Casos confirmados de Leptospirose. Brasil, Regiões e Unidades Federadas (residência). 2007 - 2019 (ano de início de sintomas). www.saude.gov.br

Daher, E. F., Abreu, K. L. S., \& Silva Júnior, G. B. (2010). Insuficiência renal aguda associada à leptospirose. Jornal Brasileiro de Nefrologia, 32(4), 408-415. https://doi.org/10.1590/S010128002010000400010

Marinho, M. (2012). Leptospirose: fatores epidemiológicos, fisiopatológicos e imunopatogênicos. Veterinária e Zootecnia, 15(3), 428-434.

Simões, L., Sasahara, T., Favaron, P., \& Miglino, M. (2016). Leptospirose - Revisão. PubVet, 10(2), 138-146. https://doi.org/10.22256/pubvet.v10n2.138-146

Soares, J. A. S., Alencar, L. D., Cavalcante, L. P. S., \& Alencar, L. D. (2014). Impactos da urbanização desordenada na saúde pública: leptospirose e infraestrutura urbana. Polêmica, 13(1), 1006-1020.

Souza, V. M. M., Arsky, M. L. N. S., Castro, A. P. B., \& Araujo, W. N. (2011). Anos potenciais de vida perdidos e custos hospitalares da leptospirose no Brasil. Revista de Saúde Pública, 45, 1001-1008.

Histórico do artigo:

Recebido: 26 de agosto, 2020.

Aprovado: 15 de setembro, 2020.

Disponível online: 30 de outubro, 2020.

Licenciamento: Este artigo é publicado na modalidade Acesso Aberto sob a licença Creative Commons Atribuição 4.0 (CC-BY 4.0), a qual permite uso irrestrito, distribuição, reprodução em qualquer meio, desde que o autor e a fonte sejam devidamente creditados. 